\title{
Application of Cultural Heritage Health Check in the Immovable Cultural Heritage Conservation Practice in Beijing
}

\author{
ZHOU Aolei ${ }^{1}$, ZHANG Jianwei $^{2,3^{*}}$, ZHANG Jianshuo ${ }^{1}$ \\ (1.WMWB Culture Tec Ltd., Beijing; 2. School of Archaeology and Museology, Peking University; 3. Experimental Teaching Center for Virtual Reality and Simulation in \\ Archaeology, Peking University)
}

KEY WORDS: preventive conservation, preventive maintenance, cultural heritage health check, immovable heritage, risk screening, sustainable management.

\begin{abstract}
:
Taking the immovable heritage in Daxing, Changping and Fangshan Districts in Beijing as case studies, starting from direct needs of the basic level, this paper aims to explore and establish a rapid, effective, promotional and regionalized risk screening and preventive conservation methodology for immovable cultural heritage by establishing work indicators and "cultural heritage health check". Digital technologies and cloud database are used as recording and analysis tools.
\end{abstract}

\section{INTRODUCTION}

\subsection{China's policies and needs}

The discussion and practice of the concept of preventive conservation is relatively late in China. It was introduced by some institutions such as Southeast University and related experts in 2010(Wu Meiping, Zhu Guangya, 2010). In recent years, the State Council and National Cultural Heritage Administration have repeatedly stressed the importance of cultural heritage safety and preventive conservation. Article Two of the $13^{\text {th }}$ Five-year Plan for the National Development of Cultural Heritage Activities, i.e. "Earnestly Increase the Efforts in Cultural Heritage Conservation", points out at the start that we should "stick to the principle of guiding according to categories, highlight the key aspects, strengthen the basis, and pay attention to both the rescue-oriented and preventive conservation approaches instead of only the rescue-oriented one." More attention for the "preventive conservation" is clearly required; and at the same time, it also notes that as for the immovable cultural heritage, we should "normalize and standardize the preventive conservation and introduce rules for daily maintenance, annual restoration, inspection, and monitoring" 1 . In 2018, the General Office of the State Council issued Opinions on Strengthening the Reform of Cultural Heritage Conservation and Utilization(The General Office of the CPC Central Committee and the General Office of the State Council,2018), reiterating the two shifts for the cultural heritage conservation: support the shift from the solely rescue-oriented conservation to the more comprehensive rescue-oriented and preventive conservation

\footnotetext{
${ }^{1}$ See the information on the official website of the National Cultural Heritage Administration of PRC: National Cultural Heritage Administration. National Cultural Heritage Administration publish the $13^{\text {th }}$ Five-year Plan for the National
}

approaches, and the shift from solely conserving cultural heritage to conserving both cultural heritage and its surroundings.

At the practice level, Principles for Conservation of Cultural Heritage in China (Revised 2015) clearly says that "preventive conservation measures should be undertaken to reduce the need for interventions" (Article 12). It also points out that "maintenance and monitoring are fundamental to the conservation of heritage sites" (Article 25) (ICOMOS China National Committee, 2015). In 2015, the National Cultural Heritage Administration compiled the Operation Regulations for the Maintenance of Ancient Buildings, providing a basis for carrying out daily maintenance for ancient buildings(National Cultural Heritage Administration, 2015).

\subsection{The present situation of relevant research and practice in} China

China's immovable cultural heritage is diverse and distributed across many regions. According to the results of the third national cultural heritage census, the registered number of the immovable cultural heritage was 766,722 . Among them, the number of the priority protected sites at the national level in the first eight lots was 5,058 (as of October 7, 2019), accounting for $0.66 \%$ of the total number. The rest were protected sites at the provincial level or below and registered immovable cultural heritage. Due to historical and economic reasons, the current situation of the immovable cultural heritage conservation in China is not optimistic. $17.77 \%$ are conserved in relatively poor conditions while $8.43 \%$ are conserved in poor conditions. The sum of the two accounts for $25 \%$ of the total number of the immovable

Development of Cultural Heritage Activities [EB/OL]

Government Affairs Disclosure - Planning and Plans, 2017. http://www.sach.gov.cn/art/2017/2/21/art 1030 137374.html, 2017-09-10 
cultural heritage. ${ }^{2}$

The current research and practice in the field of preventive conservation in China are still in the nascent stage. Most practice activities are concentrated on the "planned" conservation of the "star" buildings or group of buildings, i.e. the comprehensive evaluation, monitoring, test of "high level" priority protected sites at national level or world cultural heritage, such as Yingxian Wooden Tower, Suzhou Tiger Hill Pagoda, Zhengyangmen Gate Tower and Arrow Tower, Main Hall of Baoguo Temple in Ningbo, and other stand-alone buildings as well as the Forbidden City, Grand Canal, Great Wall, Dunhuang Mogao Caves, Yungang Grottoes, and other world heritage sites. These cultural heritage sites have outstanding value and distinctive characteristics. Their existing conservation projects are relatively comprehensive and systematic, but they have long cycles, involve high input, and are difficult to copy.

Comparing with those world heritage sites or high-level important architectural heritage sites, the number of the protected sites at the provincial, city, or county level and registered immovable cultural heritage sites is extremely huge. But very few preventive conservation practice activities were carried out for those "low-level" cultural heritage sites. In particular, the "preventive maintenance" (routine inspection and daily maintenance), which is aimed at all cultural heritage sites in a region, is still not available for them now. What the cultural heritage professionals at the district or county level in China face are not only individual "star" architectural heritage sites but also numerous ordinary cultural heritage sites (such as the immovable cultural heritage sites at the county level or ungraded ones) within their regions. What they urgently need to address is how to conserve the immovable cultural heritage sites in their respective regions.

Under such circumstances, we should know how to plan and manage in a scientific way to properly conserve the cultural heritage sites with the measures of preventive conservation, so that we can reverse this passive situation, move the conservation work at the basic level into a virtuous cycle, and maintain the value of the architectural heritage sites while saving labor costs and material resources. This should be regarded as a scientific issue that has broad practical significance. This study aims to develop a set of mechanisms and working methods to popularize and spread the philosophy and approach of preventive conservation to rectify the distribution of insufficient resources at the basic level.

\section{EXPLORING THE "HEALTH CHECK" APPROACH FOR THE IMMOVABLE CULTURAL HERITAGE SITES IN BEIJING}

In summary, the specific implementation of the preventive conservation methods should be a long-term, dynamic, continuous process with continuous feedback. In addition to

\footnotetext{
${ }^{2}$ See the information on the official website of the National Cultural Heritage Administration of PRC: National Cultural Heritage Administration. People's Daily: China has 766722 immovable cultural heritage sites.
}

regular inspections, daily maintenance, and monitoring of heritage sites, regular assessments, risk prevention, and management control should also be carried out for external environmental factors and deterioration causes to slow down the erosion of heritage sites and maximally reduce unexpected disaster damage.

Aiming at the inspection and maintenance performed in preventive conservation, this research team selected and drew a lesson from the mature experience of MOWA and other major institutions in regular inspections and preventive maintenance. By comparing with the human health check model, it divided the process of "cultural heritage health check" into three stages: basic information recording, disease risk analysis, and heritage monitoring and evaluation (see Figure 2, Figure 3). It also made use of digital technology and developed a cloud database as a recording and analysis tool to establish work indicators, explore and develop a set of rapid, effective, and popular preventive conservation methods for inspection and risk screening of local immovable cultural heritage sites, and gradually establish a cloud platform for cultural heritage health check in Beijing. Given the relative lack of preventive conservation of a large number of ordinary immovable cultural heritage sites in China, this research team organized and implemented the health check of cultural heritage sites in Changping District, Daxing District, Fangshan District, and other areas in Beijing.

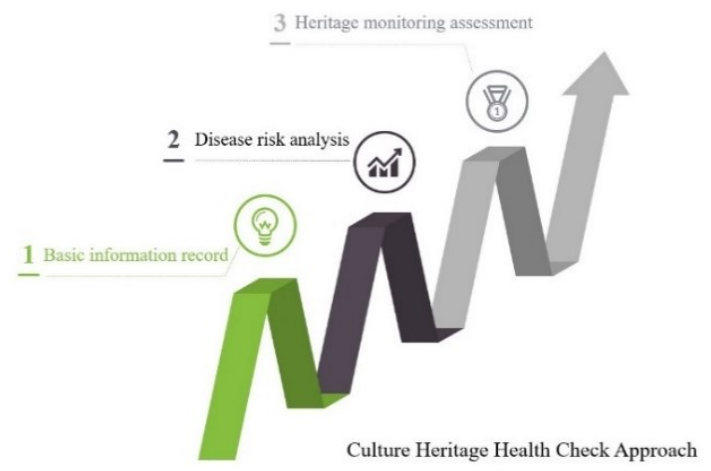

Figure 2: diagram of the three stages of cultural heritage health check approach

\subsection{Basic information recording stage}

Recording basic information is the fundamental work of the cultural heritage health check, which involves collating and collecting the information of historical literature, previous repair records, surrounding environment, conservation management, and other materials of cultural heritage. By sorting out this information according to the timeline, we can effectively provide a preliminary judgment of the main characteristics of cultural heritage, such as its architectural form, structural characteristics, reinforcement method, supporting environment, and so on. At this stage, based on the information above, the major tasks include: tracing the local structural characteristics, initially

http://www.ncha.gov.cn/art/2011/12/30/art 722 109891.html, $\underline{2011-12-30}$ 
identifying the risk impact and the process of diseases and erosion, and initially selecting the key risk points of a health check.

Taking Fangshan District as an example, as at the end of 2019, there were a total of 328 immovable cultural heritage sites in Fangshan District, including 9 priority protected cultural heritage sites at the national level, 12 protected sites at the city level, 70 protected sites at the district level, and 237 registered immovable cultural heritage sites in previous censuses. Most of the architectural heritage sites have a wooden or masonry structure. Most of the wooden buildings are beam-lifting small buildings originally built during the Ming and Qing dynasties. This kind of heritage buildings were mainly built with a load-bearing wooden structure and had a large structural safety reserve. Thus, when selecting the key risk points, priority should be given to structural deformation and damage, such as deformation, displacement, leakage, and so on. However, most of the masonry structures were pagodas and monuments built during the Qing Dynasty. When selecting the key risk points, priority should be given to local or overall deformation, inclination, settlement, and appearance quality defects (stone diseases).

\subsection{Disease risk analysis stage}

Disease risk analysis is the core work of cultural heritage health check. Its technical process is as follows:

(1) The scientific process of cultural heritage health management is initially established to study and determine the evaluation index system of the cultural heritage health check and it is taken as the basis for inspection and health check;

(2) A set of standard on-site operation procedures and technical methods is established. A rapid, effective, and targeted health check is carried out for a region according to the evaluation index system.

(3) Data are collected and analyzed. The risk levels of the immovable cultural heritage in the regions are evaluated. The data are uploaded into the cloud servers to carry out the daily management in a digital, scientific, and visual manner.

\subsubsection{Evaluation index system}

The evaluation index system had been developed according to the current standard ${ }^{3}$. A hierarchical index model is adopted to divide the main risk types into the following five categories: (1) cultural heritage safety, (2) conservation facilities, (3) architectural environment, (4) management and use, and (5) disaster risk (Table 1). Among them, the material elements of cultural heritage involved in the category of cultural heritage safety are the main

\footnotetext{
${ }^{3}$ At present, the current national standards for ancient buildings mainly include Technical standard for maintenance and strengthening of historic timber building (GB 50165-92), Technical specifications for protection of historic buildings against man-made vibration (GB/T 50452-2008), Code for lightning protection technology of ancient timber buildings (GB 51017-2014), and Ancient wall painting deterioration and legends (GB/T 30237-2013); local and industrial standards mainly include Technical code for appraiser of structural safety of ancient buildings Part 1: timber structure (DB11/T 1190.12015), Code for monitoring of heritage building safety (DB11/T 1473-2017), and Code for investigation of the protection engineering of the stone monument (WW/T 0063-2015);
}

carrier of cultural heritage value and the core content of the evaluation work. These risk types are subdivided according to different types of cultural heritage (Table 2). A subsidiary table has been made to make a statistical summary of the specific risks of each type of cultural heritage.

Table 1 Risk types

\begin{tabular}{|c|c|c|c|}
\hline $\begin{array}{l}\text { Risk } \\
\text { type }\end{array}$ & $\begin{array}{l}\text { First-level } \\
\text { directory }\end{array}$ & Second-level directory & $\begin{array}{l}\text { Risk } \\
\text { No. }\end{array}$ \\
\hline \multirow{7}{*}{ A } & \multirow{7}{*}{$\begin{array}{c}\text { Cultural } \\
\text { heritage safety }\end{array}$} & Foundation inspection & $\mathrm{A} 1$ \\
\hline & & $\begin{array}{l}\text { Inspection of main load- } \\
\text { bearing structures }\end{array}$ & A2 \\
\hline & & $\begin{array}{l}\text { Containment system } \\
\text { inspection }\end{array}$ & A3 \\
\hline & & $\begin{array}{l}\text { Material performance } \\
\text { inspection }\end{array}$ & A4 \\
\hline & & $\begin{array}{l}\text { Appearance quality } \\
\text { inspection }\end{array}$ & A5 \\
\hline & & $\begin{array}{l}\text { Structural stability } \\
\text { inspection }\end{array}$ & A6 \\
\hline & & Special inspection & A7 \\
\hline \multirow{4}{*}{ B } & \multirow{4}{*}{$\begin{array}{l}\text { Conservation } \\
\text { facilities }\end{array}$} & Firefighting & B1 \\
\hline & & Security & B2 \\
\hline & & Lightning protection & B3 \\
\hline & & $\begin{array}{l}\text { Other conservation } \\
\text { facilities }\end{array}$ & B4 \\
\hline \multirow{3}{*}{$\mathrm{C}$} & \multirow{3}{*}{$\begin{array}{l}\text { Architectural } \\
\text { environment }\end{array}$} & $\begin{array}{l}\text { Impact of environment } \\
\text { within the scope of } \\
\text { cultural heritage }\end{array}$ & $\mathrm{C} 1$ \\
\hline & & $\begin{array}{c}\text { Impact of environment } \\
\text { outside the scope of } \\
\text { cultural heritage }\end{array}$ & $\mathrm{C} 2$ \\
\hline & & Status of the carrier & $\mathrm{C} 3$ \\
\hline \multirow[b]{3}{*}{$\mathrm{D}$} & \multirow[b]{3}{*}{$\begin{array}{l}\text { Management } \\
\text { and use }\end{array}$} & Fire risks & D1 \\
\hline & & Man-made risks & D2 \\
\hline & & $\begin{array}{c}\text { Other management } \\
\text { threats or risks such as } \\
\text { unauthorized } \\
\text { construction }\end{array}$ & D3 \\
\hline \multirow{2}{*}{$\mathrm{E}$} & \multirow{2}{*}{ Disaster risk } & Meteorological disaster & E1 \\
\hline & & Geological disaster & E2 \\
\hline
\end{tabular}

Technical code for appraiser of structural safety of ancient buildings (DB11/T 1190.2-2018); Specifications of investigation for preservation engineering of earthen sites (WW/T 0040-2012); Guideline for structural safety assessment of modern historic building (WW/T 0048-2014); Code for maintenance of ancient buildings (2015). The codes for testing and evaluation of contemporary buildings include Standard for appraiser of reliability of civil buildings (GB 50292-2015); Technical standard for inspection of building structure (GB/T 50344-2004); Standard of dangerous building appraisal (JGJ 125-2016); Standard for seismic appraiser of building (GB 50023-2009); and Code for investigation of geotechnical engineering (GB 500212016), and so on. 


\subsubsection{On-site operation flow and technical methods}

\subsubsection{On-site operation flow}

During the on-site inspection, the inspection was carried out item by item according to the tables above, so as to record and collect the disease status of each part in the form of a checking record table and inspection report. The main tasks were as follows:

(1) The appearance inspection focused on checking the bearing status and appearance quality of the main structure and the main load-bearing components to find whether there was any serious damage to the structure. The priority was given to the previous summary of the key risk points and newly found weak locations of the structures.

(2) Combined with the results of appearance inspection, the necessary routine tests (such as structural deformation, material strength, etc.), measurement and non-destructive testing or noncontact special test were carried out to record the disease status in detail. At the same time, to ensure the traceability and comparability of the disease status, the model of "tracking record with a lacquered board" was adopted to take photos and record the main diseases as well information such as the name of the protected sites, the time at which photo was taken, the location and type of the disease and the specific size of the disease area (Figure 3).

(3) The conservation facilities, management and use conditions, and overall environmental features in heritage sites and the surrounding environment were recorded with on-site photos. The opinions of relevant personnel were consulted and the possible problems were summarized.

(4) According to the on-site situation, the risk coefficient was used to calculate and evaluate the severity of the various risks involved in the checking record table and provide a preliminary judgment of the conservation state of the heritage sites under the existing conditions.

\subsubsection{Technical method}

To maximally reduce the disturbance to the cultural heritage sites and their surrounding environment and realize rapid recording, reliable identification, and the comparability of follow-up work, this research team also considered the local conditions and made use of the non-contact measurement techniques such as aerial photography, panoramic view, image modeling, threedimensional laser scanning, and infrared thermal imaging to compare with the traditional test results. A digital cloud platform was used to facilitate the unified data collection and management and create each cultural heritage building's medical records.

(1) Digital records: The information was stored in the computer database by scanning, inputting, or directly collecting data information to facilitate fast and convenient retrieval, simple and efficient synchronous backup, small storage space, convenient maintenance, data security, and so on. This was a requirement for improving the management of cultural heritage conservation in the information era.

(2) Panoramic photography: The real scene of cultural heritage sites was connected by using virtual reality technology to make the spatial location and the surrounding environment clear at one glance (Figure 3).

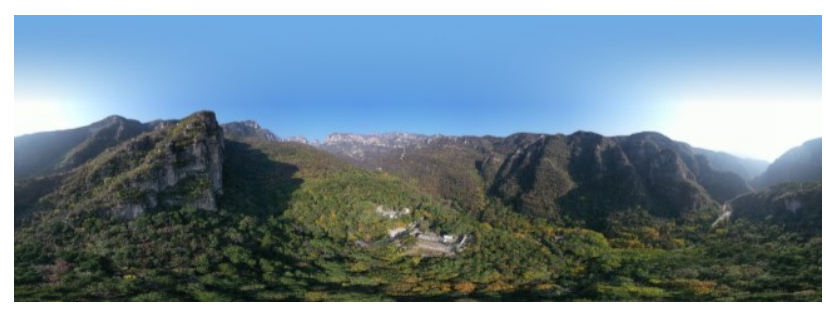

Figure 3: Display and application of panoramic photography (3) Image modeling: This is a method to obtain the whole model by analyzing and combining the image data which are composed of the basic data created by sampling discrete images. It has the characteristics of high resolution, a strong sense of reality, and accurate spatial location. It is different from Frenchstyle investigation and conventional apparent inspection, in that it can more clearly reflect the location, area, color, and other information of apparent diseases and thus is more helpful for improving the accuracy and completeness of disease identification (Figure 4).

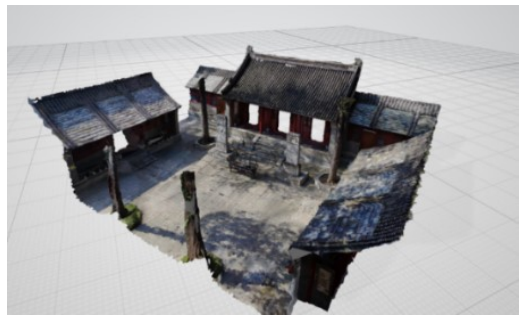

Figure 4: Application of 3D Laser scanning Technology (4) Three-dimensional laser scanning: Using the method of high-speed laser scanning measurement, we can quickly obtain the coordinates and color of each point on the object surface in a large area in high resolution and collect the true color threedimensional point cloud model to facilitate the real-time and accurate collection of cultural heritage information (Figure 5).

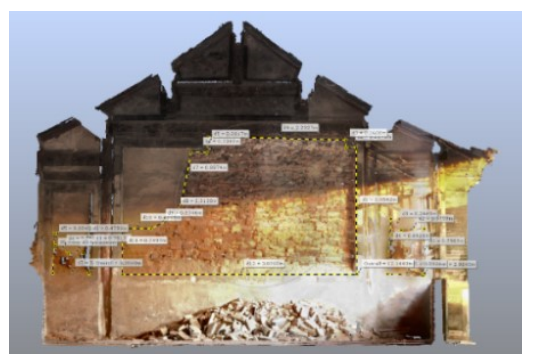

Figure 5: Application of 3D Laser scanning Technology (5) Infrared thermal imaging: Through the measurement of the change in surface temperature of a cultural heritage site, we can obtain a preliminary judgment of its surface moisture and further assess its internal water storage condition (Figure 6).

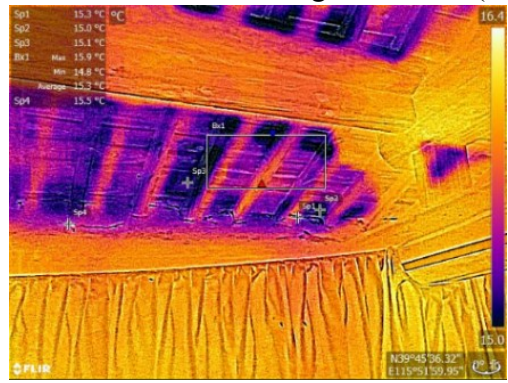

Figure 6: Application of Infrared Thermal Imaging Technology 


\subsubsection{Determination of risk levels}

We set four levels of risk to indicate the specific degree of risk. Level 1 risk: This is a high-level risk. It indicates that the conservation condition of the cultural heritage building is poor or relatively poor, the damaged areas or their combination in the load-bearing structure have affected the structural safety, the part or the whole of the load-bearing structure is in a dangerous state, and accidents may occur at any time. Reinforcement or repair measures must be taken immediately.

Level 2 risk: This is a relatively high-level risk. It shows that the conservation condition of the cultural heritage buildings is poor or average, the damaged areas or their combination in the key parts of the load-bearing structure have affected the safety and normal use of the structure. Reinforcement or repair measures are required, but there is no immediate danger. Level 3 risk: This is an average-level risk. It indicates that the conservation condition of the cultural heritage buildings is average or good, the damaged areas that have been repaired and strengthened in the load-bearing structure need to be handled again individually, and some newly discovered signs of damage need to be further observed and dealt with, but these issues do not affect the safety and use of the buildings.

Level 4 risk: This is a low-level risk where no obvious risk is shown. It shows that the conservation condition of the cultural heritage buildings is relatively good, the previous damage areas in the load-bearing structure have been dealt with correctly, no new damage areas or signs of damage have been found, and only local components are aging, which does not affect the overall structural safety and normal use of the buildings. Taking Fangshan District as an example, as at the end of 2019, there were a total of 82 protected sites at city or district level in Fangshan District, including 6 low-risk (level 4 risk) sites, 54 average-risk (level 3 risk) sites, 14 relatively high-risk (level 2 risk) sites, and 8 high-risk (level 1 risk) sites. Among the highrisk or relatively high-risk sites, there were 13 ancient buildings, 2 ancient tombs, 4 ancient sites, 2 important or monumental modern and contemporary sites, and 1 cave temple and monument, accounting for about $26.8 \%$ of the total number. The major problems were summarized as follows:

(1) Safety risks to cultural heritage

Cultural heritage safety had been the most important problem faced by cultural heritage buildings, which mainly involved three categories: foundation, main load-bearing structure, and enclosure system. A total of 67 protected sites had various degrees of safety risks, accounting for about $81.7 \%$ of the total number. Among them, 57 sites had risks in the main loadbearing structure, 22 sites had risks in the foundation, and 29 sites had risks in the enclosure system. There were risks in the load-bearing structures of protected sites within level 1 or 2 .

\section{(2) Conservation facilities}

The conservation facilities involved four areas, which were (1) firefighting, (2) security, (3) lightning protection, and (4) other conservation facilities. A total number of 29 protected sites had risks in conservation facilities, accounting for about $35.4 \%$ of the total number. Among them, 16 had risks in firefighting, 9 had risks in security, 24 had risks in lightning protection, and 4 had risks in other conservation measures. The main hidden danger is that related conservation facilities are not installed or unusable.

(3) Architectural environment

The architectural environment mainly involved three areas, which were (1) the environment within the scope of cultural heritage, (2) the surrounding environment, and (3) the supporting environment. Most of the protected sites in this physical examination showed problems in the architectural environment. There were 52 protected sites, accounting for about $63.4 \%$ of the total number. Among them, 13 had risks in the environment within the scope of the sites, 49 had risks in the surrounding environment. No obvious risks were found in the supporting environment. Most of the problems in the surrounding areas were related to building construction, industrial vibration, vegetation obstruction, miscellany stacking, and so on. These environmental conditions not only had a great impact on the architectural environment but also disturbed the protected sites. The problems in the environment within the scope of the sites were mostly caused by the random stacking of indoor miscellany, the unreasonable use of the interior space of heritage buildings, and the lack of daily maintenance.

(4) Management and use

The management and use category mainly focused on the daily management, maintenance, and rational use of cultural heritage buildings. The main risks could be divided into three categories: (1) man-made risks, (2) fire risks, and (3) unauthorized construction. Through collating the problems, we found that a total of 22 protected sites had management and use problems, accounting for about $26.8 \%$ of the total number. Among them, 9 had fire risks, 8 had man-made risks, and 6 had unauthorized construction.

According to the results predicted by the team, the main financial and human resources of Fangshan District in the next year will focus on the immovable cultural heritage within levels 1 and 2 . The limited resources have been optimized.

\subsection{Heritage monitoring and evaluation}

To facilitate the sustainable management and effective conservation of architectural heritage, this research team made use of the results of relevant on-site practices and initially established a general platform for digital records and health management of cultural heritage to materialize the unified management of architectural heritage information with Internet plus Cloud platform and digital archives technology. At present, the major functions of the platform include nine modules: (1) basic information management, (2) health check information management, (3) inspection information management, (4) "fourhave" records, (5) historical maps, (6) historical photos, (7) panoramic view data of protected sites, (8) three-dimensional data of protected sites, and (9) project management system. Besides basic functions such as data filling, data query, annual report and summary, and file output, the platform also provided the linking and display functions between geographic information cloud map system, panoramic data, and threedimensional data. In future research practice, we will continue to strengthen the processing and analysis function of heritage information and finally develop the functional modules such as the linking management of real-time data, the construction of 
early warning system, and the risk map drawing (Figure 7).

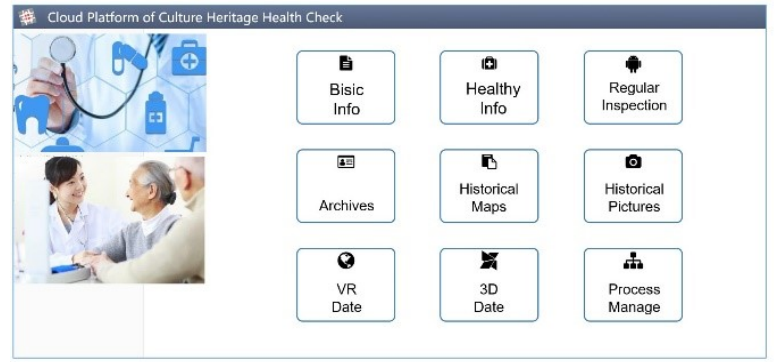

Figure 7: Diagram of cultural heritage health management and inspection system

Furthermore, this research team also made use of WeChat Mini Programs and developed an "E-routing-inspection of cultural heritage" software system to link the daily inspection of cultural heritage with the original "Internet + " cloud platform and digital records database, moving forward the daily inspection and scientific management of cultural heritage. Through cloud technology and big data support, we fully empowered the work at the basic level. We established an "online" monitoring mechanism to realize cloud inspection, cloud reporting, cloud analysis, cloud approval and encouraged public participation. This not only reduced the cost of continuous monitoring and alleviated problems caused by insufficient local cultural conservation professionals but also obtained the cultural heritage big data needed for preventive conservation and realized the traceability of cultural heritage monitoring data (Figure 8).

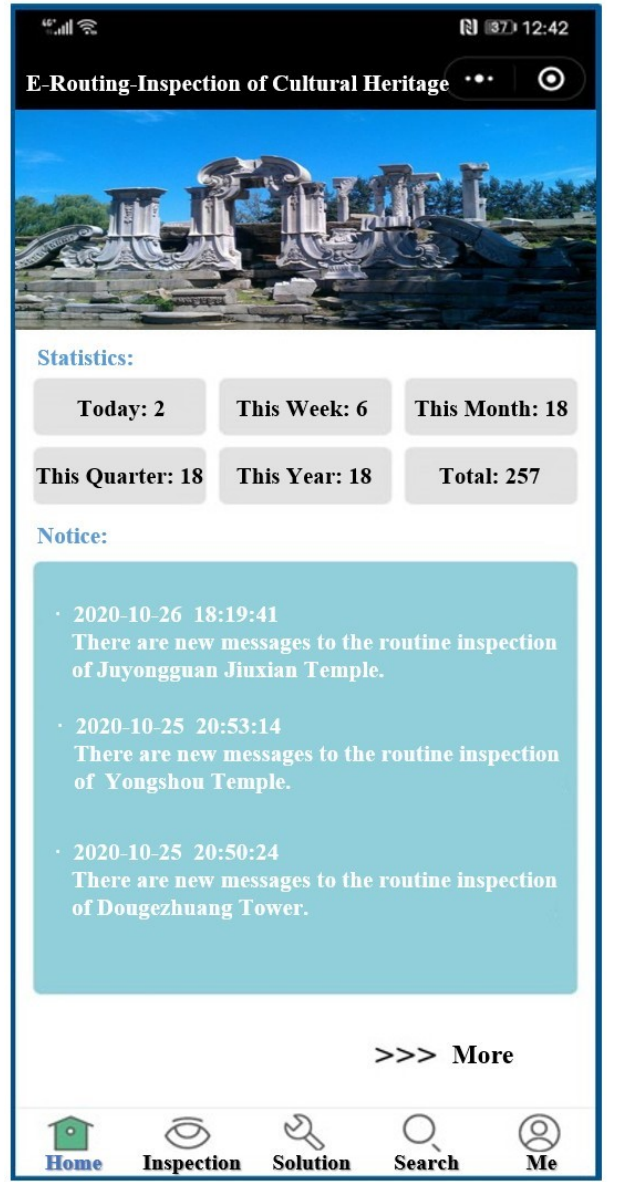

Figure 8: E-routing-inspection of cultural heritage

\section{CONCLUSION}

Preventive conservation should become an important method to facilitate the conservation and inheritance of immovable cultural heritage in China. In contrast to rescue-oriented conservation (although the two are not opposed to each other), preventive conservation is based on a long-term vision of preparation in advance. It has a macro and holistic vision and also emphasizes the implementation of specific measures such as regular inspection, data accumulation and analysis, early diagnosis, and daily maintenance within the pre-planned dynamic and continuous feedback conservation framework where the results can be predicted and controlled.

The cultural heritage health check discussed in this paper is one of the fundamental parts of the preventive conservation of immovable cultural heritage. It creates "medical records" for the immovable cultural heritage in a region, realizes early detection of risk factors and prediction of disease development. Based on the above, it carries out early intervention and prepares conservation frameworks and measures. Therefore, it can effectively support decision-making at the basic level, alleviate the contradiction between local cultural heritage conservation and fund allocation, and improve cultural heritage conservation management. Given the lack of regular inspection and maintenance practice in the conservation of immovable cultural heritage in China at the local level, this paper took the research team's practice in Beijing as an example and preliminarily explored a fast, efficient, and sustainable cultural heritage health check approach. It has achieved convincingly positive results. We hope that we can continue to carry out this approach in the future and make it available to other regions. Just like the medical examination of humans, the health check of cultural heritage should also be carried out regularly and continue to accumulate data to facilitate predictive "prevention". 


\section{REFERENCES}

Wu Meiping, Zhu Guangya, 2010: A Preliminary Study on the Preventive Conservation of Architectural Heritage. Journal of Architecture(06),37-39. doi:CNKI:SUN:JZXB.0.2010-06-011.

Rong Qingwen, Zhang Jianwei, 2019: Preventive and Planned: On the Concept and Development of "Preventive Conservation" in International Architectural Heritage Studies. Journal of Architecture(02),88-93. doi:CNKI:SUN:JZXB.0.2019-02-015.

ICOMOS China National Committee, 2015: Principles for the Conservation of Heritage Sites in China.

National Cultural Heritage Administration, 2015: Operation Regulations for the Maintenance of Ancient Buildings.

State Council's Guidance on Further Strengthening the Work of Cultural Heritage, 2016. No.17 Document of State Council. http://www.gov.cn/zhengce/content/201603/08/content_5050721.htm (6 March 2013)

Implementation Opinions of the General Office of the State Council on Further Strengthening the Safety of Cultural Heritage, 2017. No. 81 Document of General Office of the State Council http://www.gov.cn/zhengce/content/201709/20/content_5226346.htm.(9 September 2017)

The General Office of the CPC Central Committee and the General Office of the State Council issued the "Opinions on Strengthening the Reform of Conservation and Utilization of Cultural Heritage. http://www.gov.cn/zhengce/201810/08/content_5328558.htm.(8 October 2018) 